\title{
MARLOW, PERSONAGEM-NARRADOR-AUTOR.
}

Paulo Otávio Barreiros Gravina ${ }^{1}$

RESUMO: Este trabalho tem o objetivo de retornar à obra Lord Jim, de Joseph Conrad, destacando e mantendo o foco em sua força poética e em seu poder de entrelaçamento, vistos através de Marlow, que atua como personagem, narrador e autor. $\mathrm{O}$ texto analisa as diversas facetas de Marlow, em termos narrativos e poéticos, considerando seu diálogo com os outros personagens e com o leitor e também suas referências textuais ligada a outros autores, como William Shakespeare. Segundo a minha análise, a força da narrativa se dá por meio de uma rede de relações que abarca os personagens, narradores e "autores" da história em um mesmo lugar sem qualquer prioridade ou hierarquia entre eles.

PALAVRAS-CHAVE: Lord Jim, Joseph Conrad, Marlow, narrador, Shakespeare.

\section{INTRODUÇÃO}

Marlow ficou conhecido como o narrador de diversas das histórias de Joseph Conrad e, embora os motivos para a escolha deste narrador sejam um mistério, há alguns traços claros que permitem ao leitor atento reconhecê-lo e torná-lo visível. O presente trabalho tem o objetivo de desenhar alguns desses traços.

Não será, obviamente, uma imagem definida ou mesmo nítida de Marlow porque, aparentemente, Conrad não desejava um narrador claro e transparente, mas um impreciso e obscuro. E se o modelo de Conrad de contar histórias foi imitado e aproveitado por muitos (como pela principal geração de escritores posteriores a ele do cânone anglo-saxão: Fitzgerald, Hemingway e Faulkner²), isso significa um sucesso tanto de Conrad quanto, e principalmente, de Marlow.

Lord Jim será a obra em questão, ocasionalmente, também será trazido 0 Coração das Trevas, como fonte secundária ${ }^{3}$. A fonte secundária servirá não para comparar as diferenças de narração, mas para esclarecer dúvidas e destacar semelhanças no projeto literário de Conrad.

Obviamente, muitas funções de Marlow podem ser percebidas na obra, dessa maneira, não há aqui a pretensão de fazer um trabalho definitivo sobre o assunto, apenas uma descrição daquelas que podem ser consideradas as

\footnotetext{
1 Mestre em Letras pela Pontifícia Universidade Católica do Rio de Janeiro, PUC-Rio. Email:po_gravina@yahoo.com

${ }^{2}$ Harold Bloom, O Cânone Ocidental, pg. 20.

3 Já outras histórias, como Youth e Chance, que também trazem Marlow, não serão levadas em consideração.
} 
funções principais do narrador do romance de Conrad. Além disso, as funções apresentadas não se apresentam no romance com a simetria que aparentam ter neste trabalho, sendo essa simetria apenas uma visão pessoal da capacidade de Conrad (e de Marlow) de unir opostos em um mesmo ponto de vista.

Finalmente, se, como Vivien Kogut Lessa quer ${ }^{4}$, os leitores de Conrad passam a ser "colecionadores" em vez de decifradores ou definidores da obra, assumirei, portanto, eu mesmo a posição de colecionador dos discursos de Marlow e dos sonhos de Jim para tentar apresentá-los, como o primeiro, sem ordem, cronologia e importância claras, somente pela lógica não linear da percepção, que é a mesma de Marlow, ou, como quer Guimarães Rosa, por "uma linha vã, uma linha geodésica. Mais ou menos como a gente vive"5. A partir de agora, então, colecionemos.

\section{MARLOW: O NARRADOR}

Mieke Bal define o narrador como "el agente que emite los signos lingüísticos que constituyen el texto"6 e aí já aparece o primeiro problema. Em Lord Jim, Marlow aparece somente a partir do capítulo 5 como narrador da história, não sendo feita nenhuma referência a ele antes disso. Ele permanece até o capítulo 35 como o narrador da história de Jim e depois disso apenas retorna por meio de uma carta para um dos ouvintes da história. Se não narra toda a história, como Marlow pode ser o narrador de Jim?

Aí, então, já se define a primeira característica deste narrador: a incompletude. Marlow é um narrador que pertence a um tempo-espaço e possui certas limitações (por mais impressionante que seja, como mencionam alguns críticos, sua capacidade de contar a história sem pausas). Para começar, Marlow não sabe de toda a história. Ele termina no capítulo 35, aparentemente com um final feliz, porque era tudo o que sabia até ali. Igualmente, ele começa a história no momento em que conheceu Jim, sentado no tribunal.

Não há nenhuma originalidade em inscrever o narrador em um tempoespaço específicos, a novidade aqui é que Marlow não é o narrador de Lord Jim,

\footnotetext{
${ }^{4}$ Em Restos do Mapa: Fragmentos de Viagem por Grande Sertão: Veredas e Lord Jim, pgs. 1-30, principalmente.

5 João Guimarães Rosa, O recado do morro, pg. 37.

${ }^{6}$ Mieke Bal, Teoria de la narrativa, pg. 126.
} 
mas é um narrador dentro do narrador. De fato, embora a maior parte da história seja narrada por ele, é ainda uma narrativa dentro da narrativa original dos primeiros capítulos. Marlow narra através de um diálogo dentro do texto, o que já combina duas de suas principais funções: narrador e personagem. Na próxima seção, mais será desenvolvido sobre a função personagem, aqui cabe somente demarcar as características desse narrador dentro da narrativa.

Mieke Bal afirma que, quando considerado gramaticalmente, todo narrador é necessariamente de primeira pessoa. É sempre um "eu" que narra, nunca um "ele" ou "ela". Para ele, a diferença nunca está no sujeito que narra (pois este é sempre um "eu"), mas no objeto que é narrado, que pode ser um "eu" ou outro qualquer. Dessa forma, ele divide os narradores em dois tipos principais: narrador externo (NE), que fala sobre um personagem, e narrador vinculado a um personagem (NP), que é um personagem. Segundo ele:

\footnotetext{
"La diferencia entre NE y un NP, un narrador que cuenta de otros, y un narrador que habla sobre si mismo, podría relacionarme com uma diferencia en la intención narrativa. Un NP suele mantener que cuenta hechos verídicos sobre sí mismo. Puede fingir estar escribiendo su autobiografía. (...) La intención de um NE puede ser también la de presentar como verídica una história sobre otros. ${ }^{.7}$
}

Sua teoria depois se desenvolve para os níveis de foco e percepção, que seguem além do interesse neste trabalho. Pela teoria de Mieke Bal, portanto, Marlow, entraria no capítulo 5 como um personagem-narrador que mistura as funções de NE e NP. Ou seja, Marlow é um personagem e está vinculado ao personagem de Jim, sobre quem narra a história. Ou, ainda, Marlow seria apenas um personagem comum em uma história com um narrador externo e onisciente que vem desde o primeiro capítulo contando sobre Jim. Será tudo assim tão simples?

Parece bem óbvio que não. Há algo aqui que a teoria de Bal parece ignorar. Essa não é uma narrativa intercalada (pois não se entra em outro nível narrativo). Lord Jim não trata de uma história dentro de outra história, mas de um narrador dentro de outro narrador. Então qual é o verdadeiro narrador de Lord Jim, ou, antes, qual a relação entre os dois narradores?

\footnotetext{
${ }^{7}$ Idem, pg. 128.
} 
Depende, seria a resposta mais adequada. Do ponto de vista qualitativo da teoria de Bal, o narrador original (do primeiro capítulo) seria o narrador "verdadeiro" e Marlow apenas mais um personagem na história. Já do ponto de vista quantitativo, Marlow é quem narra a maior parte da história e é a sua maneira de narrar que tornou Lord Jim um clássico. Mas o principal, que a teoria de Bal ignora, é a perda de hierarquia entre esses dois (e até outros) narradores.

Os narradores no romance de Conrad se invadem, acavalam-se, nenhum possui prioridade sobre o outro. Todos possuem o mesmo direito de narrar sobre Jim. Isso fica claro mesmo antes da entrada de Marlow, quando diálogos interrompem a narrativa, por exemplo no capítulo 3 :

\footnotetext{
"Os pobres diabos dos maquinistas tinham de manter o navio em movimento de qualquer jeito, e também podiam muito bem fazer o resto; caramba, eles...

- Cale a boca - resmungou o alemão, impertubável.

(...)

Por Deus, ele já deve ter nascido irresponsável. Ele...

- Onde você conseguiu essa aguardente para beber? - Indagou o alemão, muito bravo (...). ${ }^{\text {,8 }}$
}

E no capítulo 4:

"Essa terrível atividade mental o fazia hesitar na sua fala, de vez em quando...

- O capitão continuou andando de um lado para o outro na ponte; parecia bastante calmo, apenas cambaleou várias vezes; e num certo momento, enquanto eu falava com ele, veio em minha direção como se estivesse inteiramente cego. Não respondia com objetividade àquilo que eu falava. Murmurava consigo mesmo; tudo o que consegui ouvir do que ele falava foi meia dúzia de palavras que soavam como 'maldito vaporr' e 'vaporr inferrnal' - alguma coisa relacionada com vapor. Pensei então que...

Ele estava começando a divagar (...).,9

Ocorre uma perda de importância do narrador onisciente em benefício de um perspectivismo nietzschiano ${ }^{10}$ que nega as verdades absolutas e, com elas, qualquer possibilidade de onisciência. O narrador onisciente passa a ser apenas

\footnotetext{
${ }^{8}$ Lord Jim, pgs. 27-28.

${ }^{9}$ Idem, pgs. 34-35.

10 "Concepção segundo a qual toda verdade só o é a partir, ou do interior, de uma perspectiva particular. Essa perspectiva pode ser um ponto de vista humano geral, produzido por coisas como a natureza do nosso aparelho sensorial, ou pode ser concebido como algo determinado pela cultura, pela história, pela linguagem, pela classe ou pelo sexo. Já que podem existir muitas perspectivas, existem também famílias diferentes de verdades. O termo é freqüentemente aplicado à filosofia de Nietzsche." Simon Blackburn, Dicionário Oxford de Filosofia, pg. 296.
} 
mais um ponto de vista dialogando com os personagens. Ou, como afirma Bakhtin, incluindo também o autor nessa perda de hierarquia:

"The author participates in the novel (he is omnipresent in it) with almost no direct language of his own. The language of the novel is a system of languages that mutually and ideologically interanimate each other. It is impossible to describe and analyse it as a single unitary language. $" 11$

Então o narrador original de Lord Jim não possui nenhuma prioridade sobre Marlow, que também não possui nenhuma prioridade sobre as demais vozes. Todas elas têm igual importância no que acrescentam (em termos de forma e conteúdo) na história de Jim $^{12}$. Todas são vozes dentro do texto. Mesmo Marlow é interrompido por outros personagens, por exemplo por Chester, no capítulo 14:

\footnotetext{
"Caminhava bastante devagar e abrindo as pernas ligeiramente, como se encontrasse dificuldade em se conservar em linha reta. Quase ao perdêlo de vista, pareceu-me que ele cambaleou um pouco.

- 'Homem ao mar', disse uma voz grave atrás de mim. Virando-me, vi um camarada que eu conhecia superficialmente, um australiano chamado Chester."13
}

Igualmente, Marlow parece assumir certas horas a posição de narrador onisciente e até de autor, dando a entender, em certos momentos, que comenta o personagem Jim junto com o livro Lord Jim (notavelmente no capítulo 6). No livro, parece haver um nivelamento entre autor-narrador-personagem. Ou, melhor, Marlow parece assumir, em certos instantes, as três funções.

Por fim, resta discutir os motivos que Joseph Conrad teria para escolher um narrador com essas características. Aqui, é possível apenas especular e debater algumas das ideias sobre o assunto. Para Ann Banfield, Conrad cria o que ela chama de storyteller para poder relatar os horrores do imperialismo na linguagem adequada ${ }^{14}$. A análise parece acertada, entretanto o foco dela está, obviamente, no romance $O$ Coração das Trevas. É preciso ampliá-la.

\footnotetext{
${ }^{11}$ Mikhail Bakhtin, From the Dialogic Imagination: Four Essays, pg. 333.

12 Personagem que recebe inúmeras definições ao longo do romance, desde um doido inofensivo (pg. 170) até um romântico (pg. 181). Suas ações, por sua vez, são classificadas como uma fraqueza (pg. 44), um crime (pg. 74) e, logo depois, como uma oportunidade (pg. 77).

${ }^{13}$ Lord Jim, pg. 139.

${ }^{14}$ Ann Banfield, From Unspeakable Sentences: Narration and Representation in the Language of Fiction, pgs. 533-534.
} 
Conrad, em seu romance, demonstra em várias passagens certa desconfiança com a linguagem, ou com a capacidade da linguagem de significar: "O som do sincero depoimento que prestava confirmava sua firme opinião de que, para ele, a palavra não tinha mais nenhuma utilidade. "15 Esse ceticismo lingüístico parece também estar presente nos diversos mal-entendidos que surgem no texto por causa de palavras com uso diferente (por exemplo vira-lata e Jewe/16), da confusão de Jim com George (que ficou morto no navio) ${ }^{17}$, com o trânsito entre culturas ou a confusão entre o inglês e o francês e o inglês e o alemão (ou entre Marlow e o tenente francês e entre Marlow e Stein) ${ }^{18}$ e mesmo com a loucura do maquinista-chefe ${ }^{19}$. As palavras não mais parecem designar as coisas e a linguagem, no romance de Conrad, parece ser uma construção.

Igualmente, as referências à Jim parecem ser sempre vagas, imprecisas, incompletas. Não se sabe exatamente quem é Jim, ele é indefinido, ou melhor, definido de muitas maneiras por muitas vozes. Por Marlow, por exemplo:

"Não pretendo dizer que compreendi esse homem. As impressões que
ele me deixava ter dele mesmo eram como aqueles relances em que
enxergamos através de brechas num nevoeiro denso - partículas de
detalhes vívidos e evanescentes, que não dão idéia do aspecto geral de
uma região. Eles alimentam nossa curiosidade, sem satisfazê-la: não
têm utilidade como meio de orientação. Acima de tudo, Jim era
enganoso. Foi como eu o resumi para mim mesmo, depois que ele me
deixou, já bem tarde naquela noite."

A imagem da névoa é recorrente no romance e aqui a descrição de Jim parece ser uma descrição também do romance como um todo e da linguagem que o romance utiliza. Névoa é também a imagem que o segundo-Wittgenstein usa para descrever a linguagem:

"Quando se considera o exemplo do $\S 1$ [a definição de linguagem de Santo Agostinho], talvez se pressinta em que medida o conceito geral da

\footnotetext{
${ }^{15}$ Lord Jim, pg. 36. Outros exemplos podem ser encontrados, por exemplo, nas páginas 113,121 , 154, 211 e 212. Já em $O$ Coração das Trevas, ainda mais notavelmente, nas páginas 42, 6973 , 85 e 110 , entre outras.

${ }^{16}$ Respectivamente das páginas 66-69 e 238-239.

${ }^{17}$ Das páginas 98-106.

${ }^{18}$ Respectivamente nos capítulos 12-13 e 20-23. Notavelmente na pg. 203, por exemplo.

19 No capítulo 5. John Batchelor, ampliando a análise, afirma que: "Chapter 5 reproduces this crime in a form so distorted and grotesque that its effect is to put it beyond the reach of moral judgement". John Batchelor, Lord Jim, pg. 88.

${ }^{20}$ Lord Jim, pg. 71.
} 
significação das palavras envolve o funcionamento da linguagem com uma bruma que torna impossível a visão clara."21

A solução, para dissipar a névoa segundo Wittgenstein, seria uma descrição da linguagem em seu uso, ou dos jogos de linguagem, o que forneceria uma visão panorâmica e perspícua da linguagem, sem os inevitáveis problemas trazidos quando se tenta definir um "porquê" da linguagem:

"Dissipa-se a névoa quando estudamos os fenômenos da linguagem em espécies primitivas do seu emprego, nos quais pode-se abranger claramente a finalidade e o funcionamento das palavras." 22

A linguagem em seu uso é exatamente o que faz Conrad através do dialogismo de Marlow. Marlow aparece aqui como uma espécie de demiurgo que dá sentido às coisas, que faz Jim e sua história terem significado. A solução para o ceticismo lingüístico de Conrad (consciente ou inconscientemente) parece ser Marlow:

\begin{abstract}
"And we should recall that the readiest way for putting at least a temporary stop to Marlow's own excessive fluencies was to imagine another speaker in the situation, and thus transform his unsequential and reflexive monologue into dialogue.

(...)

So again it might seem that language cannot take care of itself, and that the only cure for its hereditary disease has to come from somewhere else.

(...)

If language is always the employment of language-games, then our way of speaking are entwined not only particularly, with temporary ways of acting and talking, but also, more generally, with human 'forms of life'; and I suggest that the 'dialogic figure' of liguistic behavior that I have been describing [Marlow] is a perfect example of the latter, and therefore may be available to us even when the former are not.,23
\end{abstract}

Se análise aqui contida estiver correta, então a função de Marlow como narrador vai muito além de narrar. Há no romance delineado um confronto ${ }^{24}$ entre cultura (ou linguagem) e natureza, entre o que é natural e o que é construído, entre escuridão e luz, sendo a escuridão tudo o que existe fora da linguagem, o

\footnotetext{
${ }^{21}$ Ludwig Wittgenstein, Investigações Filosóficas, pg. 15.

22 Idem, mesma página.

23 James Guetti, Monologic and Dialogic: Wittgenstein, Heart of Darkness, and Linguistic Skepticism, pgs. 261-262. O texto se refere ao Marlow de O Coração das Trevas o que, porém, neste caso não exclui o Marlow de Lord Jim da análise.

${ }^{24}$ Principalmente em $O$ Coração das Trevas, mas também em Lord Jim, como uma espécie de projeto literário de Joseph Conrad.
} 
indizível, extralinguístico, aquilo que as palavras não alcançam ou, como define Hillis Miller:

"In Conrad's view civilization is the metamorphosis of darkness into light. It is a process of transforming everything unknown, irrational, or indistinct into clear forms, named and ordered, given a meaning and use by man,"25

Ainda sobre o indizível, Peter Pál afirma que:

\begin{abstract}
"Agamben recorda que os antigos distinguiam com cuidado o plano do nome (onoma) e o do discurso (logos). Antístenes, ainda antes de Platão, havia insistido pela primeira vez que das substâncias simples e primeiras não pode haver logos, apenas nome. Nesse sentido, o indizível não é de modo algum aquilo que não pode ser demonstrado na linguagem, mas aquilo que na linguagem pode apenas ser nomeado. Dizível, em contrapartida, é aquilo de que se pode falar num discurso definitório, embora eventualmente lhe falte um nome próprio. Entre o dizível e o indizível, a fronteira se dá no interior da linguagem, e não fora dela."26
\end{abstract}

Marlow como narrador, então, parece ser aquele que dá sentido às coisas, que tenta assimilar a natureza pela cultura, que nomeia o indizível, que consegue ver um significado onde há apenas o horror, o horror. ${ }^{27}$

\title{
MARLOW: O PERSONAGEM
}

Nem tudo é assim tão obscuro em Lord Jim. Embora todos os elementos de incerteza (da linguagem, cultura e civilização já mencionados) estejam presentes, há alguns pontos que ligam o romance em uma espécie de rede de relações que dá sentido a tudo. Essa rede ${ }^{28}$ não significa algo completamente perceptível, mas ao contrário, assemelha-se bastante a uma pintura impressionista:

'Conrad is often referred to as an 'impressionist' and the Preface can be quoted to support this: 'My task which I am trying to achieve is, by the

\footnotetext{
${ }^{25}$ Hillis Miller, Poets of Reality, pg. 14.

26 Peter Pál, A Potência de Não: Linguagem e Política em Agamben. Em: http://www.rizoma.net/interna.php?id=326\&secao=artefato.

${ }^{27}$ Aqui, obviamente, a análise aponta bem mais para O Coração das Trevas do que para Lord Jim, mas também para Lord Jim no sentido de uma ausência de lógica, de linearidade e de pontos fixos que será discutida nas próximas seções.

28 "Imagine a fat furry spider with green head and shining points for eyes, busily at work, some dewy morning, on a marvelous web - and you have the plot of Lord Jim. It spins itself away, out of nothing, with side tracks leading, apparently nowhere...". John Batchelor, Lord Jim, pg. 28.
} 
power of the written word to make you hear, to make you feel - it is, before all, to make you see!' But 'to make you see' is not only a matter of achieving the exact equivalent of sensory apphrehension of light which was the achievement of the impressionist painters, but it is also a matter of eliciting from the reader recognition that what is being presented is the truth, "29

Nesta realidade borrada, quem se move em todas as direções nessa rede é Marlow, como autor-narrador-personagem. E, como personagem, Marlow age. $E$ isso é a única coisa clara no romance: as ações entre os personagens têm, de alguma forma, significado. Nessa rede emaranhada de confusões, incertezas e perspectivismo, o agir e o narrar (estando o narrar dentro do agir) permanecem incólumes. De alguma maneira, ainda há algum sentido em agir e narrar, mesmo que esse sentido seja obscuro.

Seguindo esse raciocínio, Jim é o personagem inadequado, a borboleta pródiga e escorregadia ${ }^{30}$, cujas ações não correspondem ao pensamento. Jim quer, mas não é. O diálogo entre estética e ética aqui toma uma feição complicada, pois o desejo existe no personagem e ele quer o dever, mas este último já não existe mais. Eis o que ocorre com um idealista em um mundo niilista: romantismo, indefinição, dúvidas e incapacidade de agir.

Dessa forma, quando Marlow diz que Jim é "um de nós" ${ }^{31}$ parece ser disto que ele está falando: de um idealista, de um sonhador, de um herói em um mundo onde não cabe mais o heroísmo. Marlow é uma espécie de mentor e pai de Jim (pois entende sua situação e tenta ajudá-lo) ao mesmo tempo que amigo (pois os dois não se localizam e não pertencem, exceto na relação um com o outro). Aí está um outro sentido dessa relação narrador-personagem.

Também parece ser nesse sentido que Jim não é "suficientemente bom"32, porque "ninguém é suficientemente bom"33 em um mundo onde já não

\footnotetext{
${ }^{29}$ Idem, pg. 9.

30 "'Nunca ouvi um entomologista discorrer desta forma. Obra-prima! E o homem?' 'O homem é admirável, mas não é uma obra-prima', disse ele, olhos cravados na caixa de vidro. 'Talvez o artista estivesse um tanto louco, não é? O que você acha? Às vezes me parece que o homem veio para onde não era bem-vindo, onde não havia lugar para ele; não fosse assim, por que ele iria querer o lugar inteiro? Por que ele correria de um lado para outro, fazendo tanto alvoroço em torno de si mesmo, falando sobre as estrelas, amassando as folhas de grama?...'

- 'Coletando borboletas', intervi. (...)”. Lord Jim, pg. 177. A imagem da borboleta é recorrente em todo o romance.

${ }^{31}$ Em diversas ocasiões Marlow confirma essa opinião, a primeira vez é logo quando conhece Jim, na página 44.

32 Declarado por Marlow para Jewel na pg. 270.

${ }^{33}$ Dito logo abaixo, na mesma página.
} 
mais existe bem e mal. Jim nunca pode alcançar seus sonhos e pensamentos, pois estes (assim como as palavras) são uma construção que nunca corresponderá ao mundo. É nesse desnível que reside o drama de Jim. Como afirma John Batchelor, em uma análise de enorme discernimento:

\begin{abstract}
"It is an inverted version of the pattern of Crime and Punishment: Jim experiences guilt, agony and self-division, as Raskolnikov does, but the crime is, in a sense, minor (nobody, except the donkey-man with the weak heart, has died) and the punishment will be self-inflicted when it comes. If Dostoievsky's novel is tragic, then Conrad's resists generic classification: it is partly farce, partly tragedy, partly history. It is a problem drama turning on the destiny of an antihero, a study of a Hamlet or a modern existential hero, a work that proclaims itself as acknowledging but transcending its literary precedents and dramatic models. 34
\end{abstract}

Entretanto, como mencionado, há ainda coisas que se salvam dessa descrença e é aí que Marlow é uma figura essencial. Muitas vezes foi dito que o romance trata da "consciência", da "dignidade", da "honra", do "amor" ou da "amizade" 35 , mas o que querem dizer esses valores neste mesmo mundo?

Ora, como sugerido pela seção anterior, assim como o significado, esses valores passam a se dar em termos da relação entre os personagens, com o uso. Em um mundo indefinido, tais conceitos só podem aparecer e serem reconhecidos na prática. Também daí vem a importância de Marlow como personagem: participando. Marlow tenta arranjar um lugar para Jim; Marlow ajuda Jim, logo depois do julgamento, a arranjar um emprego; Marlow contata Stein (que envia Jim a Patusan); Marlow vai conferir o "mito de Jim" em Patusan; Marlow conforta Jim com suas dúvidas ainda em Patusan; e, principalmente, quando tudo falha, Marlow narra a história de Jim e o mantém vivo. Se Jim e Marlow de nada sabem, pelo menos eles não sabem juntos e compartilhar a ignorância já é torná-la, dialeticamente, mais coerente.

Se o romance é uma rede sem pontos ou direções definidas, e os personagens não podem sair dessa rede (assim como o homem não pode sair do mundo), o convívio dentro dessa rede surge como o único sentido possível. Voltando à comparação com Crime e Castigo, se Raskólnikov mata tentando sair do mundo, Jim morre exatamente tentando entrar nele. Poderia aqui ser feita uma

\footnotetext{
${ }^{34}$ Obra citada, pg. 97.

${ }^{35}$ Vide John Batchelor, Lord Jim, pg. 203-209, onde todos esses conceitos são apresentados.
} 
leitura com base no existencialismo de forma bem evidente (no sentido do homem tentando tornar-se objeto ou unir o em-si e o para-si sartrianos ${ }^{36}$ ), entretanto em vez de aprofundar esse conceito, é mais interessante para o presente trabalho concluir o traçado de Marlow como personagem.

Para terminar, se falta finalidade ao romance e desígnio aos personagens (ou o telos dos gregos, que diferencia a ação final da ação incompleta) e se, portanto, não há fim, só meio, sendo neste meio aonde se dá tudo, inclusive o convívio, é Marlow, o personagem, e só Marlow que faz o convívio desde o início valer a pena. Se Jim chegou a ser feliz em algum momento, é somente por causa de Marlow. O ponto fixo está exatamente na relação entre eles. Sem Marlow não haveria Lord Jim.

\section{MARLOW: O HISTORIADOR}

As últimas duas seções do trabalho trataram de Marlow respectivamente como um contador de histórias e como um participante na história. Esta tratará de Marlow como organizador da história, ou um historiador. Pela leitura do texto, fica muito claro que Marlow não narra os eventos cronologicamente ou mesmo linearmente (o que corresponde às já relatadas características dele como narrador e personagem). Marlow vem e vai, sua narrativa é interrompida pelas falas e pelas histórias de outros personagens. Marlow incorre em inúmeras digressões (desde que entra, no capítulo 5), e algumas vezes antecipa eventos que estão por vir da narrativa (por exemplo no capítulo 12, quando se esclarece que nenhum dos peregrinos do navio Patna morreu antes de relatar que o navio não afundou; nunca é dada, porém, uma imagem clara dos eventos).

A própria entrada de Marlow é um salto no tempo-espaço na narrativa, do navio prestes a ser abandonado para o tribunal, onde Marlow e Jim se conhecem pela primeira vez.

36 "Um contraste típico da filosofia de Husserl e de Heidegger e crucial na obra de Sartre O ser e o nada. Ser para-si (pour-soi) é o modo de existência da consciência, o qual consiste na sua própria atividade e na sua natureza intencional; o ser em-si (en-soi) é o ser auto-suficiente, irregular e contingente das coisas comuns. (...)". Simon Blackburn, Dicionário Oxford de Filosofia, pg. 356. 
Pode-se notar também certas preocupações de Marlow com a maneira que está contando a história. Há uma preocupação em criar uma noção da passagem exata do tempo:

"- Tudo aconteceu em bem menos tempo do que eu levo para contar, pois estou tentanto reproduzir para vocês, numa fala pausada, um efeito instantâneo de impressões visuais"37

E também com um suporte espacial para localizar a história, por exemplo no capítulo 28 em que Marlow conta de sua partida de Patusan:

"Estranhamente, na noite daquele mesmo dia (que seria o meu último em Patusan), me defrontei mais uma vez com a mesma pergunta sobre as insondáveis razões do destino de Jim... E isso me recorda da história de amor dele. 38

E então Marlow parte para uma digressão sobre amor e mulheres para, duas páginas depois, sem qualquer outra referência, retornar à Patusan, à cena de como conheceu Jewel:

"Eu ouvi esse nome pela primeira vez dez minutos depois de chegar ao
pátio da casa, quando, depois de quase arrancar meu braço, ele se
precipitou pelas escadas e começou uma alegre e pueril algazarra à
porta que ficava sob o pesado beiral." 39

A narrativa parece não seguir nenhuma lógica exata, exceto a das emoções que cada cena desperta em Marlow. As ideias e pensamentos sobre cada caso e cada personagem vão se deslindando segundo a memória de Marlow, seguindo uma importância poética e, portanto, ilógica. Marlow tem uma sensação, daí a nomeia, então a idealiza por meio de digressões poéticas e a cristaliza no concreto, depois partindo para a história que quer narrar ${ }^{40}$. As cenas, como Marlow as descreve, causam uma impressão enorme no leitor, mas é impossível formar uma cronologia exata delas (mesmo fazendo um estudo profundo da obra), tem-se apenas uma noção do que veio antes e depois, sem qualquer exatidão ou precisão.

Walter Benjamin, atento para as mudanças na maneira de narrar histórias e preocupado com a incapacidade de narrar que percebe em seu tempo, em seu

\footnotetext{
${ }^{37}$ Lord Jim, pg. 48.

${ }^{38}$ Idem, pgs. 234-235.

39 Idem, pg. 237.

${ }^{40} \mathrm{O}$ episódio já descrito do capítulo 28 é, entre muitos outros, notável nesse sentido.
} 
texto clássico O Narrador, parece compreender muito bem o tipo de "historiador" elaborado em Marlow. Segundo ele:

"A narrativa (...) é, por assim dizer, uma forma artesanal de comunicação. Sua intensão primeira não é transmitir a substância pura do conteúdo, como o faz uma informação ou uma notícia. Pelo contrário, imerge essa substância na vida do narrador para, em seguida, retirá-la dele próprio. Assim a narrativa revelará sempre a marca do narrador, assim como a mão do artista é percebida por exemplo na obra de cerâmica,41

É este narrador único, artesanal, inconfundível que aparece em Marlow. Desenvolvendo o raciocínio, Benjamin sugere que a recordação era a propriedade fundamental dos primeiros narradores e historiadores (a deusa Mnemosina, segundo ele a musa dos autores épicos):

\begin{abstract}
"A recordação inaugurou, assim, a corrente da tradição que transmite de geração para geração os acontecimentos verificados. Ela representa os elementos artísticos inerentes à obra épica, no sentido mais lato, e integra esses elementos na obra. Cumpre mencionar entre eles, e em primeiro lugar, o narrador. A recordação fornece os elementos àquela rede, formada ao fim pelo conjunto de todas as estórias. Uma liga-se à outra, tal como os mais destacados narradores - e principalmente os orientais - sempre timbraram em demonstrar. Subsiste em cada uma delas, uma Scherazade, que se lembra, em cada um dos trechos de suas estórias, de uma nova estória. Eis a memória épica e o caráter artístico da narrativa. (...) Anuncia-se aqui a memória eternizante do romancista, em oposição à recordação interessante do narrador. Aquela é dedicada a um herói, a uma viagem aventurosa ou a uma luta; esta consagra-se a muitos eventos esparsos. $\dot{E}$, em outras palavras, a lembrança que, como elemento artístico, filia-se no romance à memória, o elemento correspondente na narrativa, depois de a unidade de sua origem ter-se perdido na recordação, quando da decadência do poema épico. ${ }^{42}$
\end{abstract}

Então, que tipo de historiador é Marlow? Um que se recorda, que parte das lembranças, das sensações mais sutis no momento em que a cena aconteceu. Marlow participa narrando e narra participando. Marlow é, no sentido em que a palavra assume em Benjamin, um narrador.

\title{
MARLOW: O POETA
}

Esta seção pretende estudar a principal forma de digressão presente no texto: aquela construída poeticamente através de imagens oníricas. Há muitos

\footnotetext{
${ }^{41}$ Walter Benjamin, O Narrador: Observações acerca da obra de Nicolau Lescov, pg. 67.

42 Idem, pg. 73.
} 
casos aqui a serem relatados e quaisquer tentativas de classificá-los teriam um enorme problema metodológico: como classificar sonhos, já que os sonhos são exatamente aquilo que não é concreto, aquilo em que o mundo se liquefaz?

Não há uma resposta fácil para esta pergunta (a não ser que se siga a via psicanalítica, que não é o caso), entretanto, antes de partir para uma análise, é muito importante destacar o diálogo de Marlow com outro poeta: William Shakespeare.

Há muitas passagens de Lord Jim que ecoam Shakespeare, como por exemplo: "Era tão engraçado que até os anjos choraram"43, com a fala de Isabel em Medida por Medida: "sua essência frágil como vidro, semelhante a um símio colérico, representa comédias tão grotescas diante do céu que faria chorar os anjos (...)"44. Depois: "piscava os olhos de uma forma respeitosa, como a dizer: 'Sabemos o que sabemos'."45, com a fala de lago, em Otelo, o mouro de Veneza: "Nada me pergunteis: o que sabeis, sabeis."46. Ainda mais uma vez: "Todo mundo sabe de um ou dois assim', disse Stein, 'e essa é a dificuldade - a grande dificuldade..."'47, com a fala de Hamlet em Hamlet, príncipe da Dinamarca: "Morrer... dormir! Dormir!... Talvez sonhar! Sim, eis aí a dificuldade!"48. Nesta última parte, inclusive, Shakespeare materializa-se na fala de Stein e todo o discurso do último sobre "como ser" e sobre sonhos parece se assemelhar muito com o "ser ou não ser" do monólogo de Hamlet (de onde também é tirada a fala acima), o que é destacado por Marlow:

"Ele balançou a cabeça; em sinal de aprovação, acho. 'Já!ja! Em geral,' e usando as palavras de seu grande poeta: 'Eis é a questão...' Ele continuou balançando a cabeça, compreensivo... 'Como ser! Ach! Como ser! $!^{\prime 49}$

Shakespeare, como autor, também aparece citado no romance:

"Eu vi três livros no meio da confusão; dois pequenos, de capa escura, $e$ um volume grosso verde e dourado - obras completas de Shakespeare, de meia coroa. 'Você lê isso?' - perguntei. 'Sim. É a melhor coisa para

\footnotetext{
43 Lord Jim, pg. 92.

44 William Shakespeare, Medida por Medida, pg. 159. A tradutora do livro destaca a semelhança entre essas duas passagens.

${ }^{45}$ Lord Jim, pg. 162.

${ }^{46}$ William Shakespeare, Otelo, o mouro de Veneza, pg. 783.

47 Lord Jim, pg. 185.

48 William Shakespeare, Hamlet, príncipe da Dinamarca, pg. 568.

49 Lord Jim, pgs. 181-182.
} 
encorajar um homem', disse ele, apressado. Fiquei chocado por sua opinião, mas não havia tempo para uma conversa sobre Shakespeare. ${ }^{50}$

E, finalmente, até o já mencionado ceticismo lingüístico de Conrad parece estar de perfeito acordo com a famosa citação "palavras, palavras, palavras"51 de Hamlet. Ademais, Shakespeare baseia sua linguagem no seu uso popular, cunhando e reunindo um imenso vocabulário que não fazia parte do vernáculo inglês da época. Já Conrad também faz isso, mas com todo o estranhamento de um poliglota que não escreve em sua língua materna. De certa maneira, onde Shakespeare começa construindo uma língua, Conrad termina a colocando em suspeita.

O diálogo com Shakespeare é bem evidente e já foi apontado por muitos críticos, que, ocasionalmente, exageram essa relação. Não incorrerei no erro de comparar os dois autores em termos de conteúdo. Um escreve dramas elisabetanos e marcadamente aristocráticos no século XVI a partir de mitos préexistentes na literatura. O outro escreve romances (ou novels) imaginosos no complexo pós-romântico no século XIX, já com fortes características do modernismo. Qualquer comparação de Hamlet e Jim também encontrará diversas barreiras. Um tem suas próprias falas e tem um ator o representando. O outro é apenas visto de forma bem confusa e incompleta através das imagens poéticas de Marlow.

Mas seja no subjetivismo hesitante (e maneirista) de Hamlet ou no idealismo romântico de Jim, como destacado, há sim alguns pontos de contato entre eles na questão de como ser, da ação e do destino. Mostra-se aí o que há de universal nos dois personagens e nos dois autores. Pois embora a pergunta de Hamlet de "ser ou não ser" seja diferente da de Jim de "como ser", elas variam sobretudo na forma, mas não tanto no conteúdo. E, se algo é aprendido na resposta trágica de ambos os personagens, já que é impossível escapar ao destino, algo de novo é trazido e aprendido por Jim e esse algo vem justamente através de Marlow. A saída do subjetivismo se dá exatamente nessa complexa

50 Lord Jim, pgs. 202-203. É interessante a referência porque aqui também parece se referir ironicamente, de novo, tanto ao episódio como ao livro como um todo pois, afinal, todo o livro pode ser entendido como uma conversa sobre Shakespeare.

${ }^{51}$ William Shakespeare, Hamlet, príncipe da Dinamarca, pg. 558. 
rede de relações destacada anteriormente sem um centro no sujeito: tudo passa a se dar na interação. Pois, afinal, como já dizia o poeta: “'Sozinho, serás nada.”52

É com a interação, portanto, que morre o autor, morre o narrador, morre o personagem e morre o sujeito. Eles morrem para dar lugar a Marlow. Este, também poeta, arrisca algumas composições próprias:

\begin{abstract}
"Nada mais difícil do que dizer 'não tenha medo!' Nada mais difícil. Como se mata o medo? Eu me pergunto. Como se atira no coração de um fantasma? Como se corta uma cabeça espectral para retirá-la pela garganta espectral? É uma tarefa que se assume em sonhos, nos quais ficamos satisfeitos quando nos salvamos com o cabelo molhado e as pernas tremendo. A bala não foi fundida, a espada não foi forjada, o homem ainda não nasceu; mesmo as palavras aladas da própria verdade caem aos seus pés, como pedaços de chumbo. Para esse encontro desesperado, é necessária uma flecha encantada e envenenada, mergulhada numa mentira sutil demais para ser encontrada neste mundo. Uma tarefa para um sonho, meus senhores!"53
\end{abstract}

Porque se há algo que liga todos nós no tempo é, antes da história, a poesia que, por mais que varie na forma em cada cultura, no seu conteúdo, naquilo que há de humano, ela varia muito pouco ao longo do tempo e ao redor do espaço. E, se como diz Marlow, é impossível matar o medo (assim como é impossível derrotar o destino), talvez o convívio em conjunto o torne um pouco mais suportável.

E Marlow, trovador de Jim, criador de mitos e de história, autor, narrador e personagem, Marlow continua narrando. Mas por que ele continua narrando se este mundo não possui um sentido que o ultrapassa e se a linguagem é falha para abarcá-lo? Além disso, como explicar todo o sentido existente nas palavras e na poesia de Marlow e em sua relação com Jim? Simples: o sentido está nas relações que existem dentro do livro e que são trazidas à vida na própria relação do leitor com Lord Jim.

Finalmente, Marlow é poeta pois esta é a única posição possível em um mundo como o de Jim. Sendo impossível classificar seus sonhos e imagens poéticas dentro de uma lógica exata e fechada é, como se tentou fazer aqui, possível poetizá-los.

\footnotetext{
52 William Shakespeare, Soneto VIII, pg. 818.

${ }^{53}$ Lord Jim, pg. 268.
} 


\section{CONCLUSÃO}

Foi feita uma tentativa, através deste trabalho, de retornar à obra Lord Jim, de Joseph Conrad, destacando e mantendo o foco em sua força poética e em seu poder de entrelaçamento, vistos através do personagem(-narrador-autor) Marlow. Segundo a análise aqui contida, essa força se dá por meio de uma rede de relações que abarca os personagens, narradores e "autores" da história em um mesmo lugar sem qualquer prioridade ou hierarquia entre eles.

Somente o leitor, brevemente mencionado, ficou de fora da rede e aproveito este momento para incluí-lo. Nesse sentido, a experiência mimética é posta em suspenso e o livro deixa de ser uma imitação para se tornar uma realidade, cuja rede abarca tudo que existe.

Apresentando semelhanças com o deus Hermes, ou aquele que circula pelos três níveis, Marlow seria o único que se movimenta livremente pela rede, o senhor do tempo, do espaço, da história e da poesia. Marlow seria a borboleta que milagrosamente ganhou o dom do diálogo.

Se esse dom tem alguma valia serve exatamente como a fórmula de saída do ceticismo que atravessa a obra de Conrad e como solução para o que é chamado hoje de "peste da linguagem". Pois mesmo sendo evidente que a linguagem é uma construção, seu significado ainda pode ser encontrado por meio do diálogo, nesta rede de relações que se chama mundo.

Finalmente, sendo cada borboleta única e todas, como Stein, em algum momento, têm que dar adeus às demais, que o adeus seja como o que dá neste momento o autor deste trabalho: um adeus dialogando, sempre dialogando com o resto da coleção, até que nada mais exista e só reste o horror, o horror.

\section{REFERÊNCIAS BIBLIOGRÁFICAS}

BAL, Mieke. Teoría de la narrativa (Uma introducción a la narratologia). Segunda Edición. Catedra, Madrid - 1987.

BAKHTIN, Mikhail. From The Dialogic Imagination: Four Essays. In: Theory of the Novel: A Historical Approach, pgs. 321-353. Edited by Michael Mckeon. The Johns Hopkins University Press, Baltimore \& London - 2000. 
BANFIELD, Ann. From Unspeakable Sentences: Narration and Representation in the Language of Fiction. In: In: Theory of the Novel: A Historical Approach, pgs. 515-536. The Johns Hopkins University Press, Baltimore \& London - 2000.

BATCHELOR, John. Lord Jim. Unwin Hyman Ltd, London - 1988.

BENJAMIN, Walter. O Narrador: Observações acerca da obra de Nicolau Lescov. In: Os Pensadores, pgs. 63-81. Abril S.A. Cultural e Industrial, São Paulo - 1980.

BLACKBURN, Simon. Dicionário Oxford de Filosofia. Consultoria da edição brasileira de Danilo Marcondes. Jorge Zahar Editor, Rio de Janeiro - 1997.

BLOOM, Harold. O Cânone Ocidental. Tradução de Marcos Santarrita. Editora Objetiva, Rio de Janeiro - 1995.

CONRAD, Joseph. O Coração das Trevas. Tradução e Introdução de Marcos Santarrita. Ediouro, Rio de Janeiro - 1996.

de Janeiro - 2002. . Lord Jim. Tradução de Julieta Cupertino. Editora Revan, Rio

GUETTI, James. Monologic and Dialogic Wittgenstein, Heart of Darkness, and Linguistic Skepticism. In: The Literary Wittgenstein, pgs. 251-266. Edited by John Gibson and Wolfgang Huemer. Routledge, London and New York - 2004.

KOGUT Lessa de Sá, Vivien. Fragmentos de viagem por Grande Sertão: Veredas e Lord Jim. Dissertação de Mestrado. Departamento de Letras, PUC-RJ - 1997.

MILLER, Hillis. Poets of Reality Six Twentieth-Century Writers. Atheneum, New York - 1969.

PÁL, Peter. A Potência de Não: Linguagem e Política em Agamben. In: http://www.rizoma.net/interna.php?id=326\&secao=artefato.

ROSA, João Guimarães. O recado do morro. In: No Urubuquaquá, no Pinhém, pgs. 27-105. 9a edição. Editora Nova Fronteira, Rio de Janeiro - 2001.

SHAKESPEARE, William. Hamlet, príncipe da Dinamarca. In: Obra Completa Volume I, pgs. 529-619. Estudo Crítico de C. J. Sisson; Ensaio Histórico, Cronologia e Nota Introdutória de Oscar Mendes; Sinopses, Dados Históricos e Notas de Rodapé a cada obra, de F. Carlos de Almeida Cunha Medeiros. Editora Nova Aguilar, Rio de Janeiro - 1989.

Otelo, o mouro de Veneza. In: Obra Completa Volume I, pgs. 705-787. Estudo Crítico de C. J. Sisson; Ensaio Histórico, Cronologia e Nota Introdutória de Oscar Mendes; Sinopses, Dados Históricos e Notas de Rodapé a cada obra, de F. Carlos de Almeida Cunha Medeiros. Editora Nova Aguilar, Rio de Janeiro - 1989. 
Medida por Medida. In: Obra Completa Volume II, pgs. 136-202. Notas Introdutórias de Oscar Mendes. Editora Nova Aguilar, Rio de Janeiro - 1989.

Soneto VIII. In: Obra Completa Volume III, pg. 818. Tradução e Notas Introdutória, de Oscar Mendes. Editora Nova Aguilar, Rio de Janeiro - 1989.

WITTGENSTEIN, Ludwig. Investigações Filosóficas (Os Pensadores). Tradução de José Carlos Bruni, Editor: Victor Civita. Abril S.A. Cultural e Industrial, São Paulo - 1975.

Data da Submissão: $26 / 01 / 2018$

Data da Aprovação: 26/07/2018 